\title{
A rare manifestation of Klippel-Trenaunay syndrome with bilateral chylothorax requiring surgical management-a case report
}

\author{
Nora Mayer ${ }^{1}$, Periklis Perikleous ${ }^{1}$, Katherine De Rome ${ }^{1}$, Yu Zhi Zhang ${ }^{2}$, Andrew G. Nicholson ${ }^{2}$, \\ Vladimir Anikin ${ }^{1,3}$ \\ ${ }^{1}$ Department of Thoracic Surgery, Harefield Hospital, Harefield, UK; ${ }^{2}$ Department of Histopathology, Royal Brompton Hospital and National \\ Heart and Lung Institute, Imperial College, London, UK; ${ }^{3}$ Department of Oncology and Reconstructive Surgery, Sechenov First Moscow State \\ Medical University, Moscow, Russia \\ Correspondence to: Periklis Perikleous, PhD. Harefield Hospital, Hill End Road, Harefield, Middlesex, UB9 6JH, UK. Email: Periklis.Perikleous@nhs.net.
}

\begin{abstract}
Klippel-Trenaunay syndrome (KTS) is a rare congenital disorder with pathognomonic capillarylymphatic-venous malformation (CLVM) of an extremity in association with soft-tissue and/or skeletal overgrowth. Truncal manifestation of the disorder is uncommon and rarely symptomatic but can result in chylothorax. We report on our experience with the management of chylothorax in Klippel-Trenaunay syndrome, in a unique case of a 57-year-old female patient with metachronous bilateral chylothoraces requiring sequential surgical pleurodesis procedures, to draw attention to potential challenges posed by the pathophysiology of this uncommon manifestation. In our experience, surgical management of chylothorax in KTS should be minimally invasive. Thoracic duct ligation is not recommended, mainly due to overexpression of lymphatic collaterals, and because of theoretically possible reflux of chyle to the lower part of the body. Pleural biopsies anywhere but the point of entry should be avoided as they may result to significant concomitant chyle leak. Limited intra-operative tissue handling is advised, to reduce the risk of prolonged leakage, and utilisation of modern local haemostats should be prioritised over cauterization techniques. Nutritional status plays an essential role in chylothorax treatment, we recommend intraoperative insertion of a central line for post-operative total parenteral nutrition as a standard and lastly, considering the course of our case, we further recommend contralateral prophylactic pleurodesis or concurrent bilateral pleurodesis in KTS patients with chylothorax.
\end{abstract}

Keywords: Klippel-Trenaunay Syndrome (KTS); chylothorax; minimally invasive surgery; pleurodesis; case report

Received: 01 June 2020; Accepted: 20 October 2020; Published: 25 August 2022.

doi: $10.21037 /$ ccts-20-111

View this article at: http://dx.doi.org/10.21037/ccts-20-111

\section{Introduction}

Klippel-Trenaunay syndrome (KTS) is a rare congenital disorder $(1: 100,000)$, caused by sporadic somatic mutation in the phosphatidylinositol-4,5-bisphosphate 3-kinase catalytic subunit alpha (PIK3CA) gene. The disorder is characterised by a triad of capillary malformations, abnormal overgrowth of soft tissues and bones commonly affecting a lower extremity, and atypical varicosities (1). Mixed vascular malformations may be present, with predominantly capillary, venous and lymphatic components, without however significant arteriovenous shunting (2) which is typical of Parkes Weber syndrome. Vascular malformations may comprise areas other than the affected extremity and may vary in their depth of involvement; deep vein malformations significantly increase the risk of thromboembolism (3), while internal bleeding may occur in cases of visceral organ involvement (4). Abnormalities of the lymphatic system may range from mild lymphoedema and

\footnotetext{
^ ORCID: 0000-0002-0749-8628.
} 
lymphangiectasis to major thoracic manifestations, such as airway-compromising macrocystic mediastinal lesions (5).

Treatment for KTS is often conservative. Compression stockings can help improve pain and deformity of an affected limb, while sclerotherapy can be used to treat certain components of capillary-lymphatic-venous malformation (CLVM) such as focal venous malformations, macrocystic lymphatic malformations and bleeding lymphatic vesicles (6). Operative therapies mainly involve debulking procedures and are primarily utilized to manage specific problems, such as overgrowth (7). Truncal involvement in KTS is uncommon and rarely symptomatic. Debulking of the thoracic wall is feasible, but excision of intrathoracic and mediastinal malformations is not advised, especially if asymptomatic, because poor lymphatic drainage and altered circulation can lead to delayed tissue healing and will require prolonged use of closed-suction drainage (6).

Involvement of pulmonary lymphatics by the disease is extremely rare and there have been up to now no specific reports published in the literature discussing the incidence of chylous pleural effusion in KTS or its management. Chylothorax is typically triggered by thoracic duct injury or non-traumatic causes, however its exact pathophysiologic mechanism in KTS remains unclear. The condition can lead to significant morbidity and mortality, as leakage of lymph fluid from the thoracic duct or its tributaries into the thoracic cavity can lead to significant loss of essential proteins, immunoglobulins, fat, vitamins, electrolytes and water. Presence of chylomicrons on lipoprotein analysis and a triglyceride level of more than $110 \mathrm{mg} / \mathrm{dL}$ in the pleural fluid are diagnostic, whereas macroscopic appearance can be misleading. Management can be non-operative with tube thoracostomy, mediumchain triglyceride diet or total parenteral nutrition and octreotide/somatostatin therapy, but when conservative management options fail to provide control, minimally invasive surgery is indicated (8).

We describe the case of a patient with background history of Klippel-Trenaunay syndrome who presented with asynchronous bilateral chylothoraces requiring sequential surgical pleurodesis procedures. With this unique case report we wish to draw attention to our experience with surgical management of chylothorax in Klippel-Trenaunay syndrome and highlight potential challenges posed by the pathophysiology of this rare manifestation. We present the following case in accordance with the CARE reporting checklist (9) (available at https://ccts.amegroups.com/ article/view/10.21037/ccts-20-111/rc).

\section{Case presentation}

A 57-year-old female with a background history of KTS who had previously underwent debulking surgery of the right lower leg in 1978, presented to her local hospital with symptoms of dyspnoea. The patient's previous medical history included asthma, hypertension, hypothyroidism, type 2 diabetes mellitus, right hip septic arthritis and thromboembolism of the thoracic aorta, for which she had been on lifelong warfarin. She was diagnosed with a right pleural effusion and was drained percutaneously, with fluid cytology suggestive of lymph. The effusion rapidly recurred and the patient was referred to our institution for definitive management. On arrival, the patient was reviewed, and a planned course of action was formulated and discussed, analysing the risks and benefits of a surgical intervention. All procedures performed in this study were in accordance with the ethical standards of the institutional and/or national research committee(s) and with the Helsinki Declaration (as revised in 2013). Written informed consent was obtained from the patient for publication of this case report and accompanying images. A copy of the written consent is available for review by the editorial office of this journal. The patient also consented, as per our routine practice, to potential use of unidentifiable information from this case for purposes of research and publications.

Video assisted thoracoscopic (VATS) drainage with pleural biopsies was performed to provide symptomatic relief and obtain histological diagnosis. On examination of the thoracic cavity multiple sites of diffuse chyle leak were detected. An excisional biopsy was performed on the posterior pleura, but inadvertently triggered profuse chyle leak requiring prolonged mechanical pressure with additional use of surgical adhesives (BioGlue ${ }^{\circledR}$ ) and absorbable haemostats $\left(\right.$ SURGICEL $^{\circledR}$ ) to control. A visible net of dilated lymphatic vessels in the subpleural space indicated that ligation of the thoracic duct would not have been beneficial while any attempt for exposure of the duct would exacerbate lymphatic leakage. Contemplating the risk of protracted post-operative leak, PlasmaJet ablation of the parietal pleura was undertaken in an attempt to dry and seal remaining oozing surfaces. The procedure was completed by insufflation of sterile talc into the thoracic cavity to achieve pleurodesis. Post-operatively, the patient was treated with Octreotide and Total Parenteral Nutrition (TPN) and made a steady recovery. Warfarin was recommenced 

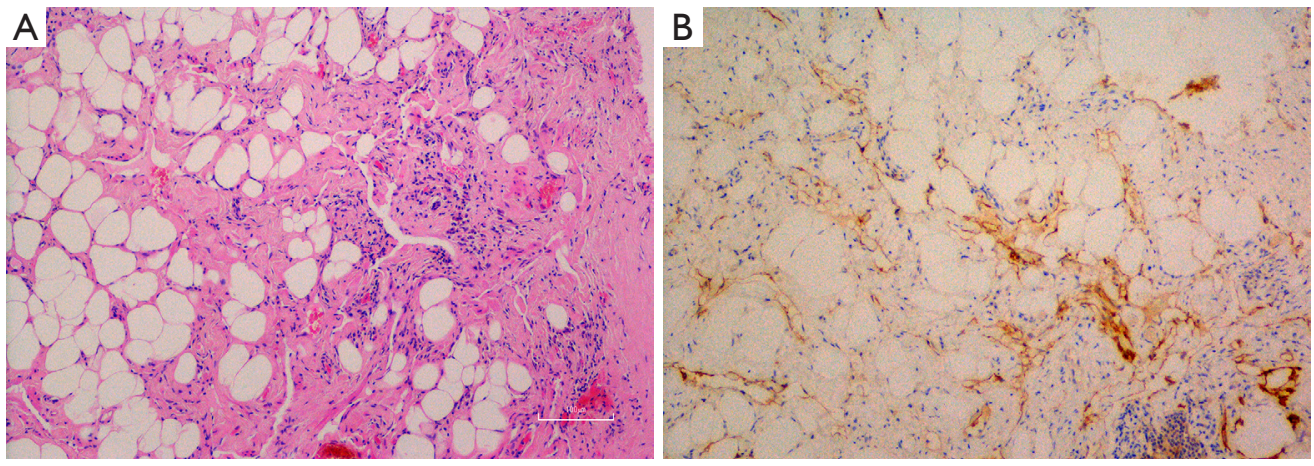

Figure 1 Lymphatic proliferation in the pleura. (A) The pleura is focally thickened by fibrosis and contains increased numbers of slit-like spaces lined by attenuated cells (haematoxylin and eosin stain, $\times 100)$. (B) These cells stain with the lymphatic marker D2-40 ( $\times 100)$.

following drain removal and the patient was discharged home 10 days after her procedure. Fluid cytology revealed a lymphocytic effusion, typical of chylous fluid. The biopsy showed focal fibrous thickening and chronic inflammation, with D2-40, a marker of lymphatic endothelium, exhibiting increased numbers of slit-like channels within the stroma (Figure 1).

The patient re-presented to her local hospital two weeks following discharge complaining of increasing breathlessness. Routine blood work revealed deranged clotting with an international normalised ratio (INR) of 5 while chest imaging showed a complex, large right pleural effusion. She was urgently transferred to our institution for a redo-procedure where initial thoracoscopic inspection of the pleural cavity confirmed the diagnosis of haemochylothorax. Due to presence of extensive adhesions between the lung and chest wall from previous pleurodesis and because of poor visualisation, conversion to a thoracotomy was deemed necessary to thoroughly drain the cavity and efficiently address all areas of bleeding and chyle leak. Following lung mobilisation and evacuation of clots, extensive use of surgical sealants (BioGlue ${ }^{\circledR}$, SURGICEL $^{\circledR}$ and HEMOPATCH) was utilised to control widespread areas of bleeding and chyle leak. Post-operatively the patient received further TPN and was discharged home two weeks later.

Eight weeks after her second hospitalisation for surgical management of the recurrent effusion, the patient again presented with respiratory symptoms at her local hospital where she was diagnosed with complex hydropneumothorax. A chest drain was positioned, and fluid cytology confirmed serous effusion with no chylomicrons. This time the patient was managed conservatively with good response to tube thoracostomy alone and was eventually discharged home with a chest drain in situ. The patient continued to be reviewed regularly in our outpatient's department and her drain was removed after two months.

During planned follow-up three months after drain removal, the patient was found to have accumulation of fluid in the left hemithorax. On this occasion, minimally invasive left thoracoscopic drainage of the effusion was undertaken, with talc pleurodesis and post-operative TPN. The patient recovered well and was discharged home one week after her procedure on medium-chain triglycerides diet. Fluid cytology showed small lymphocytes without atypia, histiocytes and scattered mesothelial cells, typical of chylous fluid. Chest imaging on routine follow-up three months after discharge showed minimal volume loss on the right with only a small opacification in the left costophrenic recess (Figure 2). The patient has since made a full recovery with no further episodes of recurrence.

\section{Discussion}

Lymphatic abnormalities are characteristically seen in the limbs of most patients with KTS whereas thoracic involvement has only been described once in the literature, in as case of a young male patient with pulmonary infiltrates, bilateral pleural and pericardial effusion (10). Because of continued large pericardial effusion, the patient required a series of pericardiocentesis procedures and eventually underwent pericardiectomy to prevent further episodes of recurrence. Our patient had a similar course, with repeat presentations due to recurrent pleural effusions, not possible to manage conservatively, requiring surgical management. 


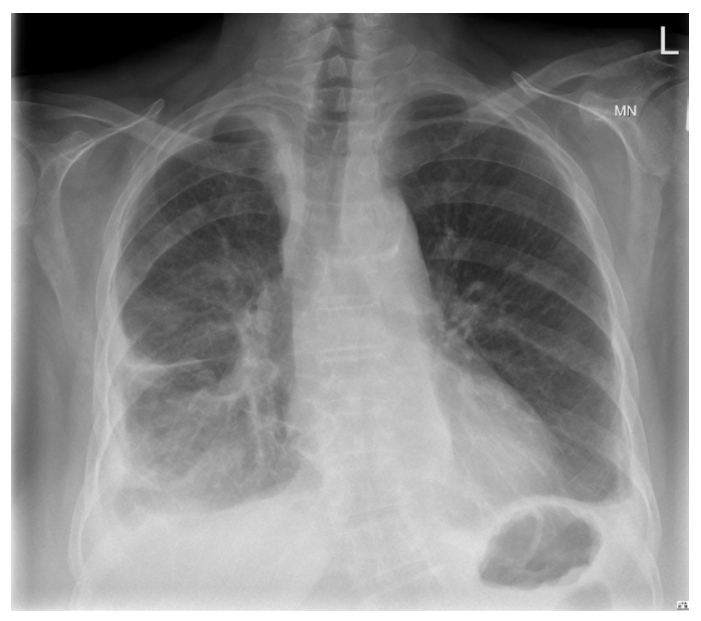

Figure 2 Posteroanterior chest X-ray showing stable postoperative changes of the right hemithorax and a small volume residual left pleural effusion.

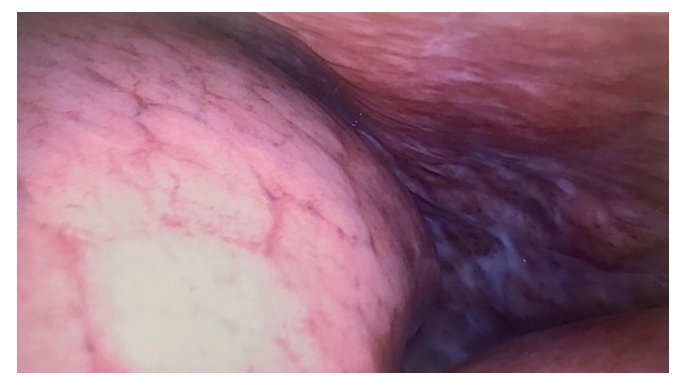

Figure 3 Lymphatic-venous malformations of the parietal pleura appear more prominent on the posterior chest wall.

In the thorax of patients with KTS lymphatic malformations are predominantly located along the retropleural space. Involvement of the posterolateral chest wall can trigger chyle leak and cause chylothorax, as evidenced by our case report (Figure 3). Due to the pathogenesis of the disease symptomatic drainage alone is likely to fail, resulting in recurrence and chronicity. Definitive treatment has to be prompt and effective to prevent deterioration due to sustained malnutrition and immunodeficiency (11).

The management of chylothorax in this patient posed a challenge to our normal practice. Pre-operative imaging in the form of lymphangiography was not performed, as a localized leakage on the basis of KTS was not expected. Intra-operatively, our attempt for an excisional biopsy from the posterior chest wall resulted in profuse leakage which was difficult to control. When the patient presented again with recurrence, substantial chyle leak was observed coming from the former biopsy site. Early recommencement of oral anticoagulant therapy postoperatively was deemed necessary due to the increased risk of deep vein thrombosis and pulmonary embolism associated with KTS and because of the patient's previous history of thromboembolism of the thoracic aorta, however warfarinisation was a critical factor to the ensuing haemorrhagic complication; retrospectively, this should have been more closely monitored in the community.

Our accumulated knowledge from managing the condition on the right hemithorax helped us apply a more effective strategy when the patient represented with contralateral pathology, allowing for an uncomplicated procedure and faster recovery. Limited intra-operative tissue manipulation helped reduce the risk of uncontrolled chyle leak while pleural biopsy was performed only at the point of entry, thus avoiding contact with the posterior chest wall entirely. To avoid haemorrhagic complications, fibrinogen and prothrombin levels were optimized perioperatively.

\section{Conclusions}

Considering the course of our case and taking KTS background information into account, we recommend considering contralateral prophylactic pleurodesis or concurrent bilateral pleurodesis in KTS patients with chylothorax. The surgical technique should be minimally invasive. Thoracic duct ligation is not recommended, mainly due to overexpression of lymphatic collaterals, and because of theoretically possible reflux of chyle to the lower part of the body. In instances of extensive leakage, modern local haemostatics can be effective and should be used instead of cauterization techniques. Nutritional status plays an essential role in chylothorax treatment, we recommend intraoperative insertion of a central line for post-operative TPN as a standard.

We acknowledge that our suggestions for management of chylothorax in KTS have only been generated from our experience with this single case, and this is a limitation of our report. We believe it is important however to be noted in the literature that management of chylothorax in KTS patients can pose significant risks for complications, especially in instances when a conventional surgical approach is employed. 


\section{Acknowledgments}

Funding: None.

\section{Footnote}

Reporting Checklist: The authors have completed the CARE reporting checklist. Available at https://ccts.amegroups. com/article/view/10.21037/ccts-20-111/rc

Conflicts of Interest: All authors have completed the ICMJE uniform disclosure form (available at https://ccts. amegroups.com/article/view/10.21037/ccts-20-111/coif). The authors have no conflicts of interest to declare.

Ethical Statement: The authors are accountable for all aspects of the work in ensuring that questions related to the accuracy or integrity of any part of the work are appropriately investigated and resolved. All procedures performed in this study were in accordance with the ethical standards of the institutional and/or national research committee(s) and with the Helsinki Declaration (as revised in 2013). Written informed consent was obtained from the patient for publication of this case report and accompanying images. A copy of the written consent is available for review by the editorial office of this journal. The patient also consented, as per our routine practice, to potential use of unidentifiable information from this case for purposes of research and publications.

Open Access Statement: This is an Open Access article distributed in accordance with the Creative Commons Attribution-NonCommercial-NoDerivs 4.0 International License (CC BY-NC-ND 4.0), which permits the noncommercial replication and distribution of the article with the strict proviso that no changes or edits are made and the original work is properly cited (including links to both the formal publication through the relevant DOI and the license). See: https://creativecommons.org/ licenses/by-nc-nd/4.0/.

doi: $10.21037 /$ ccts-20-111

Cite this article as: Mayer N, Perikleous P, De Rome K, Zhang YZ, Nicholson AG, Anikin V. A rare manifestation of Klippel-Trenaunay syndrome with bilateral chylothorax requiring surgical management-a case report. Curr Chall Thorac Surg 2022;4:31.

\section{References}

1. Gloviczki P, Driscoll DJ. Klippel-Trenaunay syndrome: current management. Phlebology 2007;22:291-8.

2. Lindenauer SM. The Klippel-Trenaunay syndrome: varicosity, hypertrophy and hemangioma with no arteriovenous fistula. Ann Surg 1965;162:303-14.

3. Baskerville PA, Ackroyd JS, Lea Thomas M, et al. The Klippel-Trenaunay syndrome: clinical, radiological and haemodynamic features and management. Br J Surg 1985;72:232-6.

4. Servelle M, Bastin R, Loygue J, et al. Hematuria and rectal bleeding in the child with Klippel and Trenaunay syndrome. Ann Surg 1976;183:418-28.

5. Duman L, Karnak I, Akinci D, et al. Extensive cervicalmediastinal cystic lymphatic malformation treated with sclerotherapy in a child with Klippel-Trenaunay syndrome. J Pediatr Surg 2006;41:e21-4.

6. Duggan EM, Fishman SJ. 71 - Vascular Anomalies. In: Holcomb GW, Murphy JP, St. Peter SD. editors. Vascular Anomalies, Holcomb and Ashcraft's Pediatric Surgery. Seventh Edition. Elsevier, 2020:1147-70.

7. Gloviczki P, Hollier LH, Telander RL, et al. Surgical implications of Klippel-Trenaunay syndrome. Ann Surg 1983;197:353-62.

8. Graham DD, McGahren ED, Tribble CG, et al. Use of video-assisted thoracic surgery in the treatment of chylothorax. Ann Thorac Surg 1994;57:1507-11; discussion 1511-2.

9. Riley DS, Barber MS, Kienle GS, et al. CARE 2013 Explanations and Elaborations: Reporting Guidelines for Case Reports. J Clin Epidemiol 2017;89:218-35.

10. Joshi M, Cole S, Knibbs D, et al. Pulmonary abnormalities in Klippel-Trenaunay syndrome. A histologic, ultrastructural, and immunocytochemical study. Chest 1992;102:1274-7.

11. Nair SK, Petko M, Hayward MP. Aetiology and management of chylothorax in adults. Eur J Cardiothorac Surg 2007;32:362-9. 